\title{
ANALISIS DAN PERANCANGAN APLIKASI E-MEETING BERBASIS WEB
}

\author{
Yen Lina; Meiliana; Sebastian Karuna Alfasan \\ Computer Science Department, School of Computer Science, Binus University \\ Jl. K.H. Syahdan No. 9, Palmerah, Jakarta Barat 11480 \\ meiliana@binus.edu
}

\begin{abstract}
Information technology is closely related to wide area networks. BINUS University pays much attention to the development of information technology. Yet, it has not applied all concepts of information technology. There are still activities carried out conventionally such as meeting activity. This is the main attraction of the authors to implement a new system. The purpose of this research is to analyze and design an e-meeting application of Computer Science Department of BINUS University. By using this application, user will be easy to conduct meeting without location barrier. This research is using analysis method on literacy study, as well as analysis on current meeting process through interview with expert and user to detect current problem. Design method usies software engineering concept, by Unified Modeling Language and Entity Relationship Diagram. UML notation explains the overview and the detail of e-meeting system. Relational database explains data structure used in this system. The result of this research is a development of e-meeting web based application to help improve meeting activity to be more effective and efficient. E-meeting application has many helpful features as used in regular meeting, as well as administration panel to control and manage user of this application.
\end{abstract}

Keywords: online meeting, e-application, $U M L, E R D$

\begin{abstract}
ABSTRAK
Teknologi informasi erat berkaitan dengan jaringan luas. BINUS University adalah salah satu dari sekian banyak universitas yang memfokuskan diri ke arah perkembangan teknologi informasi. Akan tetapi tidak semua hal dilakukan dengan menerapkan konsep teknologi informasi, masih ada kegiatan yang dilakukan secara konvensional seperti kegiatan meeting. Hal ini yang menjadi daya tarik penulis untuk menerapkan sebuah sistem yang baru. Tujuan dari penelitian ini adalah untuk menganalisis dan merancang aplikasi Emeeting pada jurusan Teknik Informatika BINUS University. Manfaatnya adalah untuk membantu memudahkan staf Teknik Infomatika dalam hal mengadakan meeting. Metode analisis dilakukan terhadap studi literatur, wawancara, dan sistem berjalan untuk mendeteksi masalah yang ada. Metode perancangan dilakukan dengan menerapkan konsep rekayasa perancangan piranti lunak yaitu unified modelling language, entity relationship diagram. Notasi UML menjelaskan garis besar serta rincian dari sistem e-meeting. Relational database menjelaskan struktur data yang digunakan dalam sistem. Hasil yang dicapai dalam penelitian ini adalah pengembangan aplikasi E-meeting berbasis web yang dapat membuat kegiatan meeting lebih efektif dan efisien. Aplikasi E-meeting ini memiliki banyak fitur yang dapat digunakan dalam meeting pada umumnya, beserta fasilitas yang tersedia untuk administrator dalam mengontrol dan mengatur pengguna aplikasi e-meeting.
\end{abstract}

Kata kunci: online meeting, e-application, UML, ERD 


\section{PENDAHULUAN}

Teknologi informasi erat berkaitan dengan jaringan luas. Dengan adanya jaringan yang luas, pertukaran informasi menjadi tersebar sehingga dapat di akses tanpa ada batasan waktu dan tempat. Internet merupakan kumpulan jaringan yang terhubung secara luas dan memiliki berbagai alat media untuk mengaksesnya. Salah satu contohnya adalah bentuk interaksi antar sesama manusia yang cukup sering ditemukan seperti chat, yaitu berbicara melalui fasilitas teks yang diselenggarakan secara langsung (real time).

E-meeting adalah sebuah kegiatan meeting yang diadakan melalui sebuah media elektronik dan menggunakan software khusus. Penggunaan e-meeting merupakan alternatif dari meeting konvensional dengan tatap muka langsung. Pada era sekarang ini banyak pengembang piranti lunak yang terus berusaha melakukan inovasi terhadap aplikasi chat tersebut. Hal ini terkait dengan meningkatnya faktor mobilitas pengguna yang tentunya ingin dapat terhubung antar sesama pengguna tanpa harus selalu berada di tempat yang sama. Salah satu contoh dari inovasi tersebut adalah tersedianya fasilitas papan tulis digital di mana pengguna selain berinteraksi melalui teks dapat juga menyampaikan pesan melalui coretan tangan layaknya di papan tulis tradisional. Namun aplikasi online yang dapat memfasilitasi kegiatan pertemuan/meeting baik secara formal maupun informal belum tersedia. Dengan online meeting yang memiliki fitur chat dan digital whiteboard memungkinkan pengguna melakukan meeting secara digital tanpa harus hadir secara langsung.

BINUS University adalah salah satu dari sekian banyak universitas yang memfokuskan diri ke arah perkembangan teknologi. Akan tetapi tidak semua hal dilakukan dengan menerapkan konsep teknologi informasi, masih ada kegiatan yang dilakukan secara konvensional seperti kegiatan meeting. Hal ini yang menjadi daya tarik penulis untuk menerapkan sebuah sistem yang baru. Oleh karena itu dilakukan analisis yang meliputi studi lapangan, dan analisis sistem, yang kemudian berlanjut ke tahap perancangan dengan menerapkan konsep perancangan piranti lunak, implementasi dan evaluasi.

\section{METODE}

Metodologi penelitian yang digunakan adalah metode analisis dan metode perancangan. Metode analisis dilakukan dengan: (1) studi pustaka, yaitu mencari informasi yang berasal dari bukubuku dan berbagai literatur yang berkaitan dengan objek penelitian. Sumber tersebut digunakan sebagai landasan teori dan alat bantu dalam menganalisis; (2) studi lapangan, yaitu meninjau sistem yang selama ini telah ada dan digunakan serta melakukan wawancara terhadap pihak-pihak yang terkait; (3) analisis system, yaitu melakukan analisis terhadap hasil pengumpulan kebutuhan sistem serta juga melakukan perbandingan terhadap sistem serupa yang pernah ada dan menyesuaikan dengan kebutuhan sistem yang akan dibuat sehingga benar-benar sesuai.

Metode perancangan dilakukan dengan: (1) penerapan konsep UML; (2) perancangan tampilan layar; (3) perancangan database.

\section{Tinjauan Pustaka}

\section{Rekayasa Piranti Lunak (RPL)}

Menurut Bauer (1968), rekayasa piranti lunak adalah pengembangan dan penggunaan prinsip pengembangan untuk memperoleh perangkat lunak secara ekonomis yang dapat diandalkan dan dapat bekerja dengan lebih baik pada mesin nyata. Dikembangkan oleh IEEE (Institute of Electrical And 
Electronics Engineers), definisi tersebut memiliki makna yang lebih luas dan lengkap, yaitu: aplikasi dari sebuah pendekatan sistematis, dan berdisiplin kepada pengembangan, operasi, dan pemeliharaan perangkat lunak, ini adalah aplikasi untuk mengembangkan piranti lunak.

Lapisan-lapisan pendekatan RPL terbagi menjadi tiga bagian utama. Pertama adalah process layer. Bagian ini adalah fondasi dari RPL yang mendefinisikan sebuah kerangka kerja untuk sekumpulan kunci proses yang harus dibangun demi keefektifan penyampaian teknologi pengembangan RPL. Kedua adalah methods layer. Bagian ini menjelaskan secara teknis bagaimana cara membangun suatu perangkan piranti lunak. Terakhir adalah tools layer. Bagian ini menyediakan dukungan otomatisdan semi otomatis untuk process dan methods. Lapisan-lapisan tersebut di dukung oleh sebuah layer pendukung yang menjadi landasan paling penting dalam RPL yaitu quality focus. Layer ini harus diisi dengan manajemen yang baik dan filosofi yang baik untuk meningkatkan kualitas dari software tersebut.

\section{Model Process Software}

Menurut Pressman (2010), ada beberapa model proses yang lazim digunakan dalam merancang suatu piranti lunak (software). model-model tersebut dapat dijelaskan sebagai langkahlangkah yang akan digunakan dalam merancang suatu software. Model pertama adalah prescriptive model. Proses model ini mendeskripsikan setiap modul yang dikerjakan. Disebut prescriptive karena mereka menentukan elemen-elemen kerangka proses, tindakan perancangan program, tugas-tugas, hasil pekerjaan, jaminan kualitas, dan mekanisme perubahan kontrol untuk sebuah projek. Setiap model juga menentukan aliran kerja yang menggambarkan keterkaitan elemen-elemen proses. Model kedua adalah waterfall model. Proses model yang terkadang disebut sebagai classic lifecycle ini menyarankan sebuah pendekatan yang sistematis dan sekuesnsial untuk pengembangan sofware yang dimulai dengan persyaratan yang diminta oleh customer, dan berkembang melalui perencanaan, pemodelan, memuncak dengan maintenance setelah projek selesai dikerjakan.

Waterfall model pada setiap langkahnya akan dirinci sebagai berikut: (1) Requirements definition - tahap ini adalah tahap awal pengumpulan data dan menetukan spsifikasi dari pengguna secara detail untuk membentuk suatu sistem; (2) system and software design - merancang bagianbagian dari sistem dalam hal spesifikasi untuk membangun aksitektur sistem, dan mengidentifikasi dan menjelaskan sistem software dan hubungannya; (3) implementation and unit testing - dalam tahap ini, sistem software diterapkan dalam kumpulan program dan subprogram. Tahap ini juga melakukan verifikasi bahwa semua program-program sesuai dengan spesifikasinya; (4) integration and system testing - melakukan pengecekan terhadap semua bagian sistem dan masing-masing hubungannya bahwa sudah memenuhi spesifikasinya. Setelah selesai, sistem dapat diberikan kepada pengguna; (5) operation and maintenance - melakukan perawatan secara berkala terhadap sistem bila sistem mengalami perubahan spesifikasi dari pengguna.

\section{Computer-Supported Cooperative Work (CSCW)}

Menurut Shneiderman (1998), definisi CSCW adalah bidang studi yang berfokus pada perancangan dan evaluasi teknologi baru untuk mendukung proses sosial kerja, seringkali di antara mitra yang berjauhan. Hasil CSCW biasanya disebut groupware. Jenis-jenis kerja sama dikelompokkan berdasarkan tujuan, antara lain: (1) kemitraan terfokus, yaitu kerja sama antara dua user yang saling membutuhkan untuk menyelesaikan tugas; (2) kuliah atau demo - seseorang membagikan informasi kepada banyak user di tempat lain. Waktunya dijadwalkan; (3) konferensi, yaitu komunikasi kelompok dengan tempat dan waktu yang berbeda; (4) proses kerja terstruktur orang yang peranannya berbeda bekerja sama dalam tugas yang berhubungan; (5) electronic commerce, yaitu kerja sama jangka pendek untuk mencari informasi dan memesan produk, dan jangka panjang untuk perjanjian atau kontrak bisnis; (6) rapat dan dukungan keputusan, yaitu rapat tatap muka menggunakan komputer dengan membuat kontribusi simultan; (7) teledemokrasi - pemerintah 
melakukan rapat jarak jauh, menampilkan komentar dewan, mencari konsensus melalui konferensi, debat, dan pemungutan suara online.

\section{HASIL DAN PEMBAHASAN}

\section{Analisis Sistem Berjalan}

Saat ini rapat FASILKOM BINUS University khususnya jurusan Teknik Informatika masih menggunakan metode konvensional, yaitu dengan whiteboard fisik dan spidol. Para peserta pun masih harus hadir langsung di ruangan pertemuan. Perangkat lunak serupa yang telah tersedia banyak di internet seperti Yahoo Messenger ${ }^{\circledR}$, Windows Live! Messenger ${ }^{\circledR}$, dan Microsoft NetMeeting. Masing-masing aplikasi ini mempunyai fitur utama seperti sistem yang akan dirancang, yaitu mampu untuk menerima input dari user berupa teks maupun coretan layaknya pena virtual. Akan tetapi fitur standar tersebut dirasa kurang memenuhi kebutuhan klien, oleh karena itu sistem yang akan dirancang diharapkan memiliki fitur tambahan yang lebih berguna.

Berdasarkan wawancara yang telah dilakukan dengan beberapa karyawan Jurusan Teknik Informatika, didapat beberapa poin sebagai berikut: (1) undangan kegiatan meeting diberitahukan melalui e-board system yang telah ada; (2) kegiatan meeting biasanya diadakan oleh Ketua Jurusan; (3) hanya tersedia dua ruang untuk mengakomodasi kebutuhan satu fakultas; (4) sering terjadi penyesuaian jadwal mendadak; (5) adanya kemungkinan anggota rapat berhalangan hadir karena alasan pekerjaan; (6) jika anggota tersebut diharuskan hadir, pekerjaan dibawa ke ruang rapat.

Dari hasil wawancara tersebut diatas, ditemukan beberapa poin masalah yang menjadi fokus dari perancangan sistem ini sebagai berikut: (1) staf jurusan Teknik Informatika membutuhkan suatu media yang memungkinkan untuk melakukan pertemuan secara maya tanpa harus menghadiri langsung, hal ini dikarenakan keterbatasan ruangan yang akan digunakan untuk pertemuan di mana sekretaris diharuskan untuk meminjam ruang kuliah setiap kali akan diadakan pertemuan; (2) staf jurusan Teknik Informatika juga membutuhkan media yang mampu untuk berbagi ide dan pendapat tertulis yang dapat lebih mudah diingat dan diarsipkan; (3) staf jurusan Teknik Informatika terkadang tidak dapat hadir karena ada kegiatan/aktifitas lain atau jika terpaksa hadir dengan membawa pekerjaan yang sedang dikerjakan sehingga mengurangi efektifitas rapat.

Beberapa pemecahan masalah diusulkan untuk menjawab permasalahan yang telah dianalisis, berupa perancangan system berbasiskan aplikasi web dengan kemampuan: (1) memudahkan staf jurusan Teknik Informatika dalam menuangkan ide yang dapat dibagi untuk bersama; (2) membantu staf jurusan Teknik Informatika dalam melakukan pengarsipan dan dokumentasi kegiatan meeting yang telah dilakukan; (3) memungkinkan staf jurusan Teknik Informatika untuk tetap dapat menghadiri meeting walau tidak berada di tempat yang sama.

\section{Rancangan Sistem yang Diusulkan}

Tujuan dari perancangan perangkat lunak ini adalah agar perangkat lunak yang dibangun dapat terencana dengan rapi dan memiliki gambaran struktur yang jelas dan lengkap.

\section{Perancangan Class Diagram} dalam sistem.

Class diagram (Gambar 3) digunakan untuk mencari atribut, objek, dan operasi yang ada 


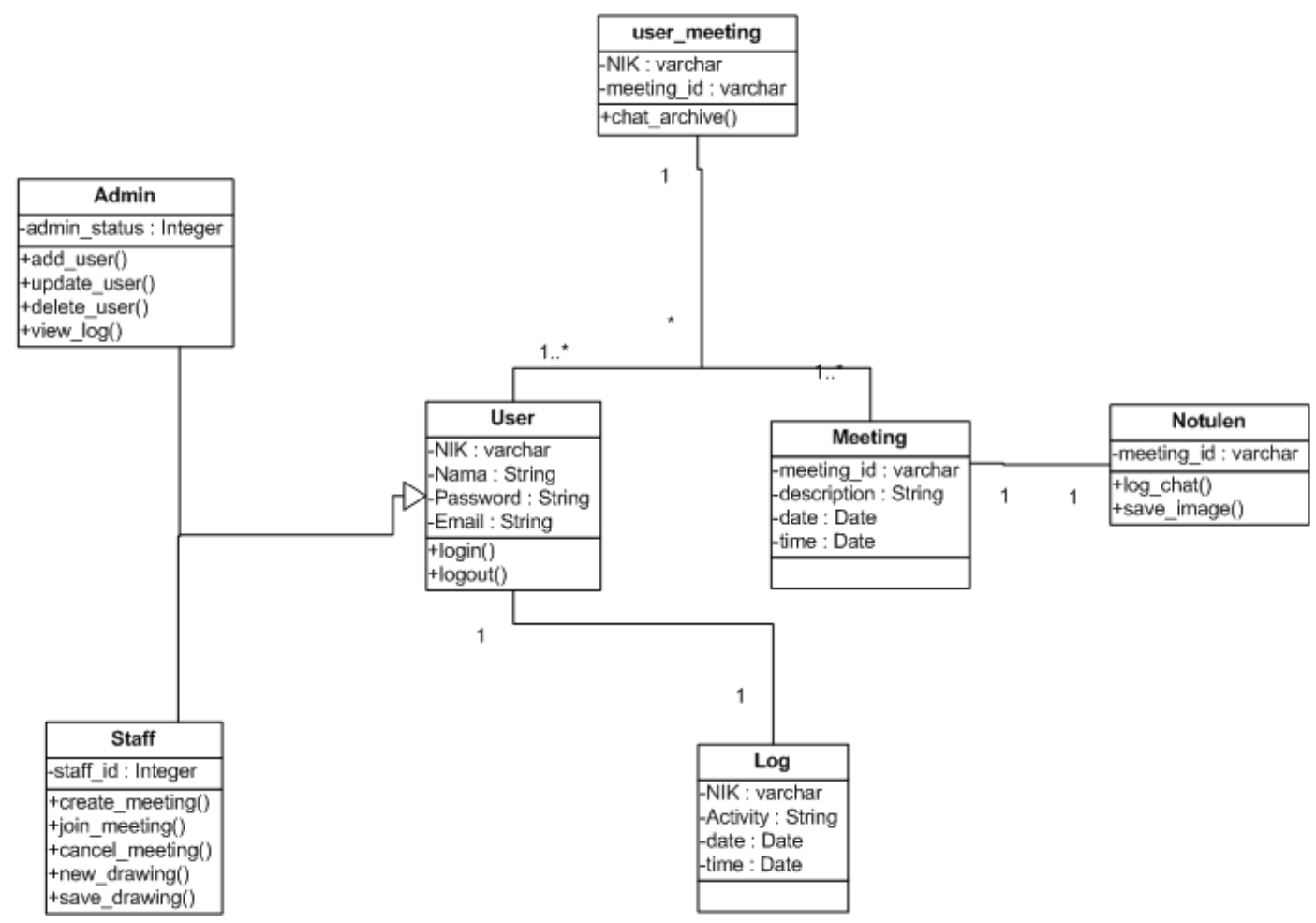

Gambar 3 Class diagram

\section{Perancangan Use Case}

Aktor pengguna web pada aplikasi ini secara garis besar dibedakan menjadi dua yaitu sebagai administrator (Gambar 4) dan user (Gambar 5).

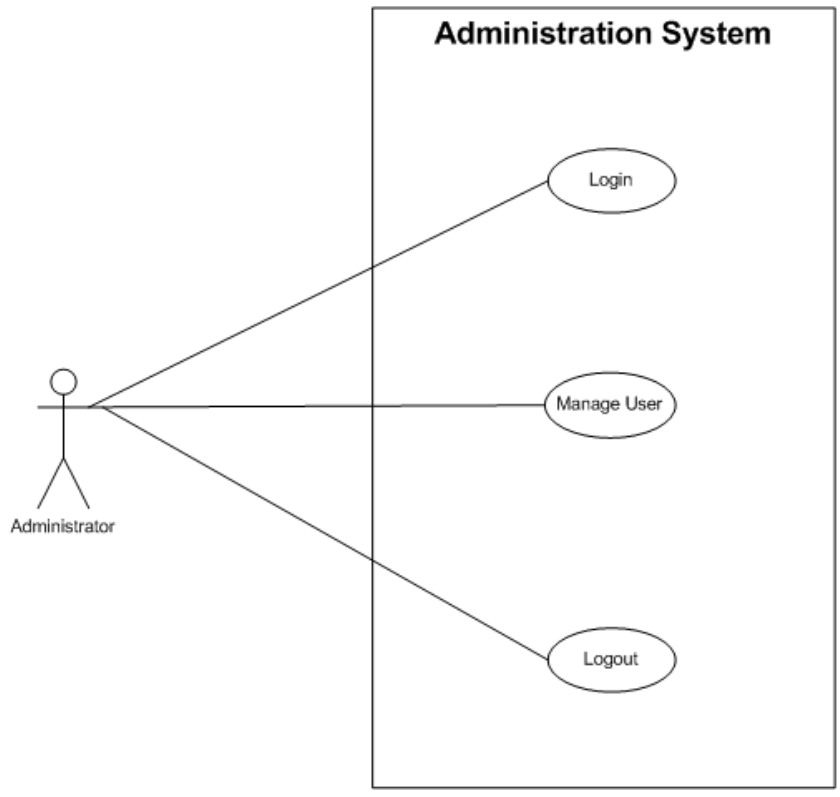

Gambar 4 Use case (admisitrator) 


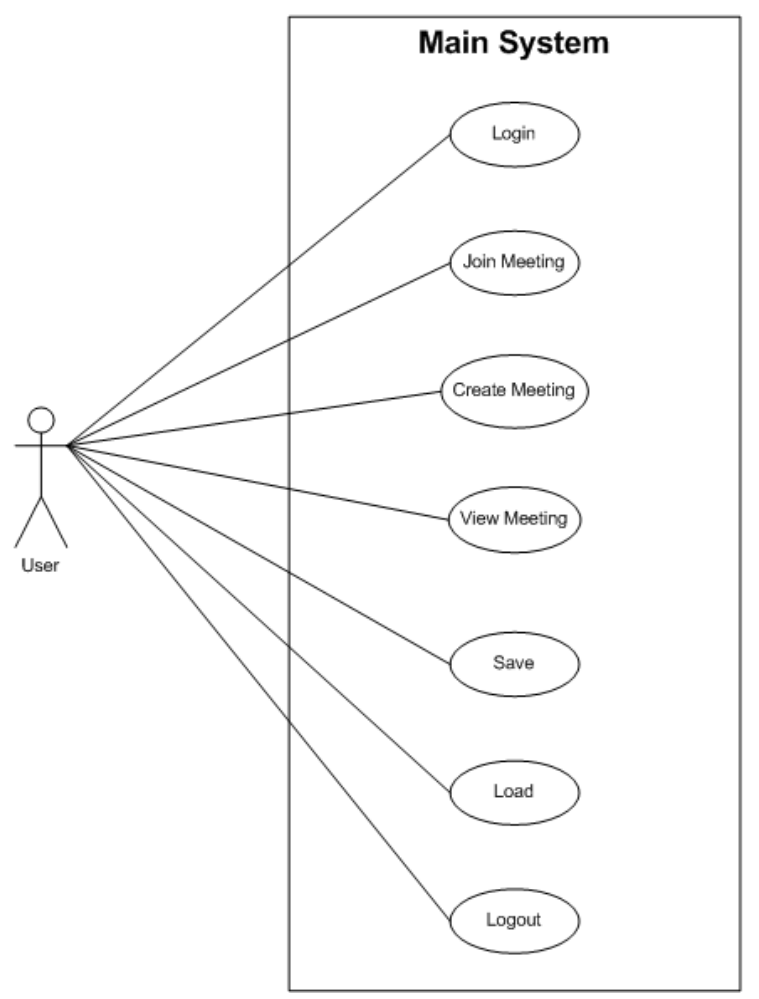

Gambar 5 Use Case (user)

\section{Perancangan Database}

Aplikasi E-meeting yang akan dikembangkan ini menggunakan empat tabel dalam databasenya. Relasi antar tabel tersebut dapat dilihat pada ERD (entity relationship diagram) pada Gambar 6. Tabel MsMeeting digunakan untuk mencatat log dari setiap user yang menggunakan sistem ini bedasarkan NIK (nomor induk karyawan). Tabel MsUser digunakan untuk menyimpan data karyawan pengguna aplikasi E-meeting ini. Data ini berfungsi untuk mengetahui detail kontak dari masingmasing karyawan tersebut, sedangkan tabel TrDetailMeeting digunakan untuk menyimpan dan menghubungkan data dari MsMeeting ke tabel MsUser. Tabel Log digunakan untuk menyimpan detail $\log$ user.

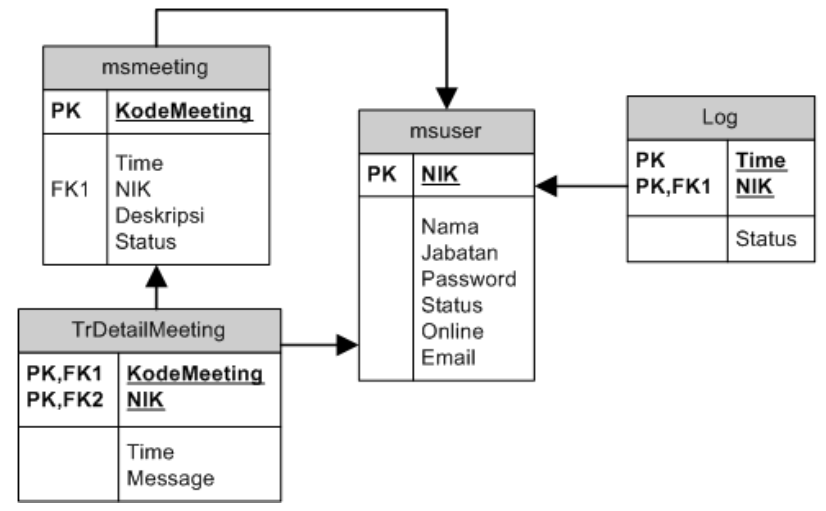

Gambar 6 Entity relationship diagram (ERD) 


\section{Evaluasi Sistem}

Implementasi dilakukan sebelum evaluasi dilakukan. Spesifikasi Hardware minimum yang diperlukan untuk komputer klien yang digunakan adalah: processor Pentium IV 1 GHz, memory 1 GB, hard disk dengan kapasitas 80 GB, dan monitor dengan dukungan resolusi 1024x768. Spesifikasi software yang diperlukan untuk komputer klien adalah: sistem operasi Microsoft Windows 2000 atau XP dan web browser berupa Internet Explorer 5 atau ke atas.

Tahap pengembangan tidak membutuhkan jaringan tertentu seperti jaringan lokal, intranet, maupun internet karena aplikasi dapat dijalankan langsung pada komputer yang sekaligus betindak sebagai server. Sedangkan tahap implementasi mutlak membutuhkan jaringan internet agar aplikasi dapat diakses oleh klien dari mana saja dan kapan saja.

Untuk evaluasi, kami melakukan uji coba langsung ke dua orang pengguna di jurusan Teknik Informatika, yang kemudian disusul dengan wawancara. Berikut hasil evaluasi dari jawaban wawancara:

1. Bagaimana menurut anda sistem aplikasi ini?

Berdasarkan percobaan yang dilakukan, sistem aplikasi ini berjalan dengan baik dan cukup memiliki fungsi yang dapat digunakan untuk kegiatan e-meeting. Alur sistemnya pun sudah baik dan tidak membingungkan.

2. Dari segi fitur, tampilan dan kemudahan apakah sudah memuaskan?

Fitur untuk saat ini sudah cukup, fitur doodle padnya cukup menarik, tetapi akan lebih baik jika ditambahkan lagi fitur seperti dukungan untuk format ppt, sehingga bisa digunakan juga untuk presentasi. Untuk tampilannya, cukup informatif walaupun sederhana.

3. Apakah ada tambahan lagi untuk sistem ini?

Seandainya nanti kalau memungkinkan, kembangkan versi mobile juga mengingat akses internet sekarang sudah lebih mudah bahkan dari sebuah telepon genggam.

Berikut adalah salah satu tampilan layar halaman meeting (Gambar 7), di mana user dapat melakukan chat antar sesama user yang hadir saat itu. Doodle pad berguna untuk menampung gambar coretan bila diperlukan. 


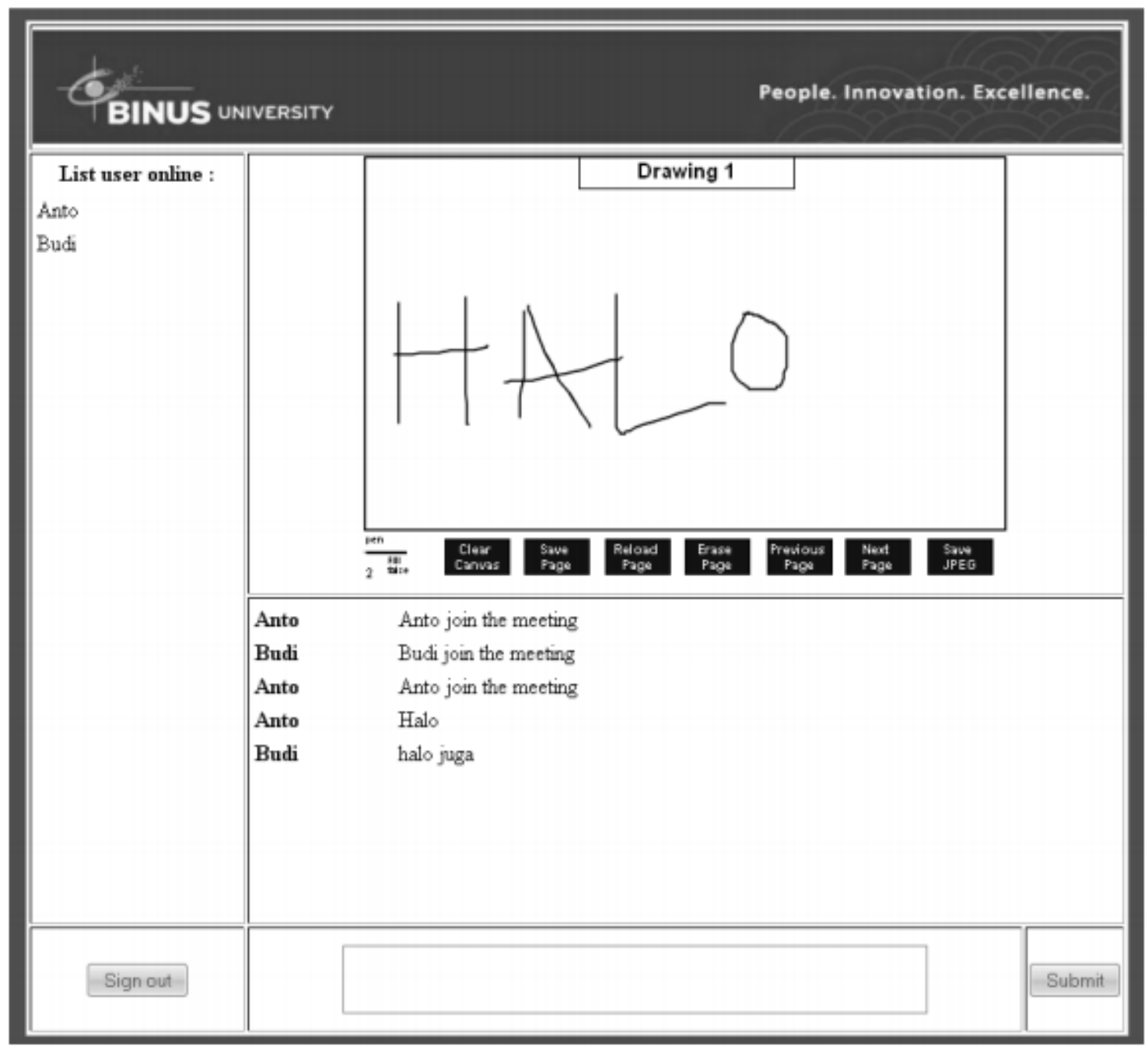

Gambar 7 Layar halaman Meeting

\section{PENUTUP}

Berdasarkan hasil analisis dan evaluasi yang telah dilakukan, dapat disimpulkan beberapa hal sebagai berikut: (1) aplikasi E-meeting yang diajukan ini merupakan alternatif yang bisa digunakan untuk seluruh staf jurusan Teknik Informatika BINUS University dalam menyelenggarakan kegiatan rapat; (2) aplikasi E-meeting yang dihasilkan mempunyai fitur yang cukup dalam menunjang kegiatan online meeting; (3) dengan adanya aplikasi E-meeting ini diharapkan kegiatan rapat yang diadakan dapat menjadi lebih efektif dan efisien; (4) fasilitas yang tersedia untuk administrator memudahkan dalam mengontrol dan mengatur pengguna serta penggunaan aplikasi E-meeting ini.

Aplikasi yang telah dirancang ini masih memiliki beberapa hal yang dapat ditambahkan untuk menunjang perkembangan aplikasi ini, yaitu: (1) sistem navigasi Doodle Pad pada aplikasi E-meeting ini masih perlu disempurnakan untuk meningkatkan fungsionalitasnya; (2) penggunaan CSS pada aplikasi $e$-whiteboard ini agar dikembangkan lebih lanjut untuk menghasilkan tampilan yang lebih menarik; (3) diharapkan ke depannya mempunyai dukungan terhadap format PDF untuk memudahkan sistem pengarsipan; (4) jika dimungkinkan, perlu dikembangkan versi mobile yang lebih kompak tetapi tidak kehilangan kemampuan utamanya; (5) sistem penyimpanan gambar hasil doodle agar 
dapat dijadikan satu dalam arsip dengan format RAR; (6) sistem meeting yang lebih handal dapat ditambahkan fungsinya dengan dukungan suara dan video.

\section{DAFTAR PUSTAKA}

Bauer, Fritz et al. (1968). Software Engineering: Report on A Conference Sponsored by The NATO Science Committee. Belgium: Scientific Affairs Division of NATO.

Pressman, Roger S. (2010). Software Engineering: A Practitioner's Approach. New York: McGrawHill.

Shneiderman, Ben. (1998). Designing the User Interface: Strategies for Effective Human-Computer Interaction (2nd ed.). Boston: Addison-Wesley. 